\title{
Auroral ion outflow: low altitude energization
}

\author{
K. A. Lynch ${ }^{1}$, J. L. Semeter ${ }^{2}$, M. Zettergren ${ }^{2}$, P. Kintner ${ }^{3}$, R. Arnoldy ${ }^{4}$, E. Klatt ${ }^{5}$, J. LaBelle ${ }^{6}$, R. G. Michell ${ }^{6}$, \\ E. A. MacDonald ${ }^{7}$, and M. Samara ${ }^{8}$ \\ ${ }^{1}$ Department of Physics and Astronomy, Dartmouth College, USA \\ ${ }^{2}$ Electrical Engineering, Boston University, USA \\ ${ }^{3}$ School of Electrical and Computer Engineering, Cornell University, USA \\ ${ }^{4}$ Space Science Center, University of New Hampshire, USA \\ ${ }^{5}$ Applied Physics Laboratory, Johns Hopkins University, USA \\ ${ }^{6}$ Department of Physics and Astronomy, Dartmouth College, USA \\ ${ }^{7}$ Los Alamos National Laboratory, New Mexico, USA \\ ${ }^{8}$ Southwest Research Institute, USA
}

Received: 9 April 2007 - Revised: 11 July 2007 - Accepted: 1 August 2007 - Published: 2 October 2007

\begin{abstract}
The SIERRA nightside auroral sounding rocket made observations of the origins of ion upflow, at topside F-region altitudes (below $700 \mathrm{~km}$ ), comparatively large topside plasma densities (above 20000/cc), and low energies $(10 \mathrm{eV})$. Upflowing ions with bulk velocities up to $2 \mathrm{~km} / \mathrm{s}$ are seen in conjunction with the poleward edge of a nightside substorm arc. The upflow is limited within the poleward edge to a region (a) of northward convection, (b) where Alfvénic and Pedersen conductivities are well-matched, leading to good ionospheric transmission of Alfvénic power, and (c) of soft electron precipitation (below $100 \mathrm{eV}$ ). Models of the effect of the soft precipitation show strong increases in electron temperature, increasing the scale height and initiating ion upflow. Throughout the entire poleward edge, precipitation of moderate-energy (100s of eV) protons and oxygen is also observed. This ion precipitation is interpreted as reflection from a higher-altitude, time-varying field-aligned potential of upgoing transversely heated ion conics seeded by the low altitude upflow.
\end{abstract}

\section{Science background and outline}

Low altitude ion energization is one of the boundary conditions of magnetosphere/ionosphere coupling. The transfer of auroral energy through precipitation, Poynting flux, convection electric fields, and Joule heating to the cold lower ionosphere provides the initiation of a process that moves atmospheric oxygen out into the far magnetosphere. Sounding rockets are ideally situated for observing the low altitude

Correspondence to: K. A. Lynch

(kristina.lynch@dartmouth.edu) signatures of auroral ion energization, providing in situ examples of both kinetic and fluid processes that can be used to constrain models of ion outflow. Their altitude range connects the low altitude fluid observations provided by radar studies to the high altitude in situ observations of spacecraft. The SCIFER (Arnoldy et al., 1996) and AMICIST (Lynch et al., 1996; Bonnell et al., 1996) experiments observed the low altitude signatures of broadband ELF (BBELF) transverse ion heating subsequently quantified by higher-altitude Freja (Andre et al., 1998; Knudsen et al., 1998a, b; Wahlund et al., 1998) and FAST observations (Lynch et al., 2002; Strangeway et al., 2005). This paper reporting SIERRA rocket observations on the nightside and Frederick-Frost et al. (2007) reporting SERSIO rocket observations on the dayside both describe even lower altitude signatures: the initiation of ion heating and upflow that may seed wave particle interactions at higher altitudes.

Data sets from radar observations (Semeter et al., 2005; Doe et al., 1993; Wahlund et al., 1993) provide lower altitude fluid observations, but are unable to follow the kinetics of wave particle interactions. Fluid moment calculations are able to model and quantify ion outflow rates up to altitudes of about $250 \mathrm{~km}$; above that, ion heating and outflow are often observed that are inconsistent with fluid calculations (Stromme et al., 2004). Sounding rocket observations, while limited to the specific case studies of their launch events, provide an important linkage between radar and satellite studies. Empirical classification (Wahlund et al., 1993) of ion upflow events as seen in radar databases into Type 1 (convection driven) and Type 2 (precipitation driven) is supported by the literature of sounding rocket observations. Both Type 1 (Moore et al., 1996; St. Maurice et al., 1976) and Type 2 (Frederick-Frost et al., 2007; Lynch et al., 1996) cases have

Published by Copernicus Publications on behalf of the European Geosciences Union. 
Table 1. SIERRA particle instrumentation specifics.

\begin{tabular}{llll}
\hline & HE & HiFixed & BEEPS \\
\hline & electrons & ions & $\mathrm{O}+, \mathrm{H}+$ \\
energy $[\mathrm{eV}]$ & $7-14500$ & 6 & $6-200$ \\
steps & 64 & 1 & 32 \\
image bins & 64 & 64 & 16 \\
time resolution $[\mathrm{ms}]$ & 2 & 2 & 4 \\
$\mathrm{G}_{O}$ & $2 \mathrm{e}-4$ & $1 \mathrm{e}-3$ & $5 \mathrm{e}-3$ \\
\hline
\end{tabular}

$\mathrm{G}_{o}$ in $\mathrm{cm}^{2} \mathrm{srkeV/keV}$. Time resolution is time per image.

been studied with sounding rockets, though there is a bias towards precipitation-driven events as the precipitation activity is often the trigger for calling the rocket launch.

Recent models of heating ( $\mathrm{Su}$ et al., 1999; Thayer and Semeter, 2004) and Alfvénic coupling (Streltsov and Marklund, 2005; Streltsov and Lotko, 2003; Chaston, 2006; Lysak and Song, 2005) are becoming more quantitative and realistic; our motivation with this paper is to provide a detailed case study as an example data set for testing these models. These data can be used in particular to address two separate questions: (1) Does ion energization play an active or a passive role in the coupling between the magnetosphere and the ionosphere, in particular in nightside Alfvénic regions? (2) What quantitative role do various magnetospheric drivers play in the outflow of ionospheric atoms to the deep magnetosphere? SIERRA thus provides a detailed case study in the framework of a larger picture: the low-altitude transfer processes in downward current/polar cap boundary regions. We use these data to study the footpoint of nightside Alfvénic coupling.

\subsection{Outline of paper}

In the following sections we first describe the SIERRA mission and its event. Then we present (in Sects. 2.3 and 3) the in situ data, showing the ion flows in the context of electron precipitation and DC electric and magnetic fields. In the Discussion (Sect. 4), we explore the localization of the ion upflows, showing that the upflow is coincident with northward plasma motion, with good Alfvénic transmission to the lower ionosphere, and with soft electron precipitation. A modelled response to the soft precipitation is given (Sect. 4.3), and shows the initiation of upflow. We consider also the somewhat larger region of ion precipitation, and the implications of ion circulation throughout the polar cap boundary region. We conclude that, for this particular event, the principal initiator of the observed upflow is the soft electron precipitation, and invite modellers to incorporate the details of these observations into nightside Alfvénic coupling models.

\section{SIERRA}

The details of the SIERRA (Sounding of the Ion Energization Region: Resolving Ambiguities) sounding rocket mission have been presented in various publications (Klatt et al., 2005; MacDonald et al., 2006; MacDonald, 2004; Samara, 2005); here we recapitulate the points of interest to our ion outflow study.

\subsection{Instrumentation}

SIERRA consisted of three payloads launched from a single 4-stage vehicle. Each payload measured electric and magnetic fields as detailed by Klatt et al. (2005). The particle instrumentation measured electron precipitation and proton and oxygen distributions, and included three spatially separated fixed energy $(6 \mathrm{eV})$ ion detectors. The electron instrument is referred to as HE for hemispherical electron detector. The proton/oxygen detector separates mass with a toroidal magnet section and is referred to as Beeps, for magnetic field energetic electrostatic particle spectrometer. The fixed energy ion detectors are called HI-fixed. The particle instruments described here were all top-hat electrostatic analysers (Carlson et al., 1983; Young et al., 1988; Lynch et al., 1994). Each payload had its spin axis roughly perpendicular to the geomagnetic field line; two payloads were in a cartwheel configuration (spin axis roughly perpendicular to payload velocity) and one was a propeller (spin axis in the plane of the payload trajectory.) Each detector was mounted so that its two-dimensional aperture plane was normal to the spin axis; thus the imaging bins spin through the observed pitch angles. Particle instrument specifics are listed in Table 1.

\subsection{Launch event}

SIERRA was launched at 08:23:05 UT (23:23:05 LT) on 14 January 2002 from Poker Flat Research Range, Chatanika, Alaska, reaching an apogee of $735 \mathrm{~km}$. The launch call resulted from a $150 \mathrm{nT}$ substorm, and the rocket trajectory followed the substorm breakup northward across Alaska, eventually overtaking the arc structures and crossing into the polar cap. The solar wind speed an hour before launch was about $400 \mathrm{~km} / \mathrm{s}$, the solar wind density was $4-5 / \mathrm{cc}$, and $B_{z}$ was southward. Ground camera data before and during the launch show a series of westward travelling surges along several large east-west extended arc structures crossing over the Poker Flat cameras. Camera coverage under apogee is poor because of cloud cover.

\subsection{Data overview}

Figure 1 provides an overview of the particle observations throughout the flight. The principal auroral features can be seen in the electron energy spectrogram in panel (a). The payload passed through a series of inverted-V arc structures until $\mathrm{T}+530 \mathrm{~s}$. At that point the electron precipitation 
(a)
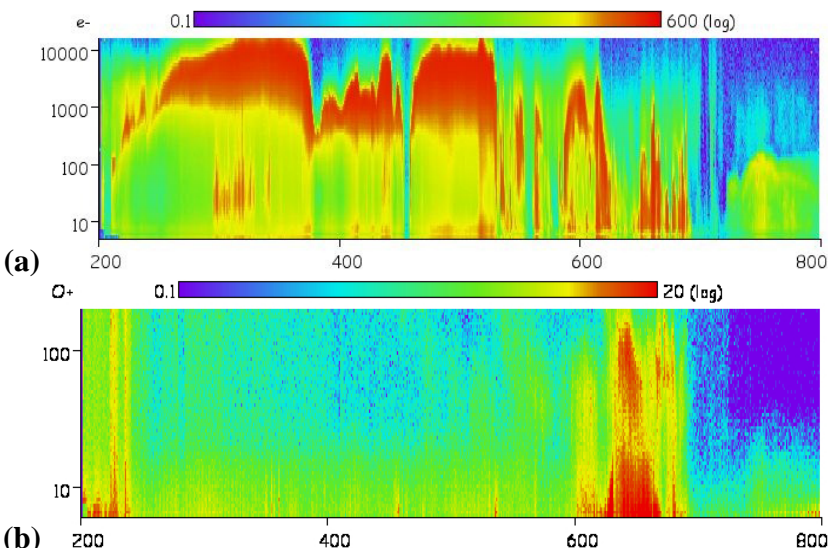

(b)

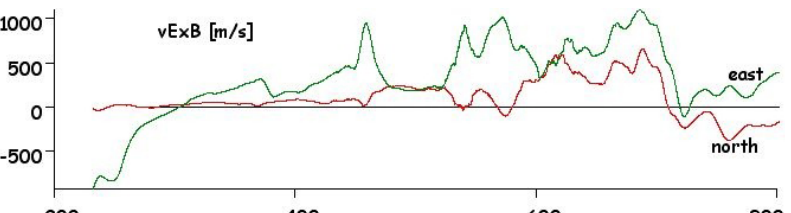

(c)

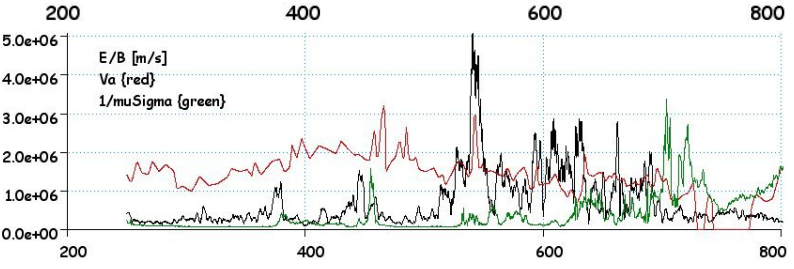

Fig. 1. Flight data overview as a function of flight time [s] from $\mathrm{T}+200 \mathrm{~s}$ to $\mathrm{T}+800 \mathrm{~s}$. (a), (b): Energy spectra [eV] of electrons and oxygen, integrated over all pitch angles [color bar proportional to differential energy flux $\mathrm{eV} / \mathrm{cm}^{2} / \mathrm{s} / \mathrm{sr} / \mathrm{eV}$, arbitrary gain.] (c) $\mathrm{DC}$ electric field perpendicular to $B_{O}$, plotted as velocity $[\mathrm{m} / \mathrm{s}]$. (d) Inverse conductivities, plotted as velocity $[\mathrm{m} / \mathrm{s}]$ : E/B, black; $V_{A}$, red; $1 /\left(\mu_{o} \Sigma_{P}\right)$, green.

changed abruptly into a polar cap boundary signature of lower energy, dispersed, field-aligned precipitation. At $700 \mathrm{~s}$, this region ends and the payload is in the polar cap with the exception of a small, weak arc structure at $\mathrm{T}+720-800 \mathrm{~s}$.

Panel (b) shows the energy spectra of oxygen integrated over all pitch angles. An inspection of Fig. 2 is helpful at this point as it illustrates the ion behavior in more detail, showing separate spectra of both upgoing and downgoing oxygen and protons. It is clear from Fig. 2 that the low-energy part of Fig. $1 \mathrm{~b}$ is predominantly upgoing, while the higher energy $\mathrm{O}+$ is precipitating. Dispersed ions of $10 \mathrm{~s}$ to $100 \mathrm{~s}$ of eV are seen throughout the polar cap boundary region; we see in Fig. $2 b$ and $d$ that these are precipitating. Faint signatures of precipitating oxygen can be seen as early as $\mathrm{T}+450 \mathrm{~s}$. Upflowing ions are seen only in the oxygen channel, and only from $\mathrm{T}+620-700 \mathrm{~s}$, at the lowest energies. Why this upflow region is limited to this narrow channel is the subject of discussion below. Also seen in the ion data are signatures of lower hybrid solitary structures (i.e., T+450 s) (Lynch, 1999). These are seen as low energy bursts throughout the region of
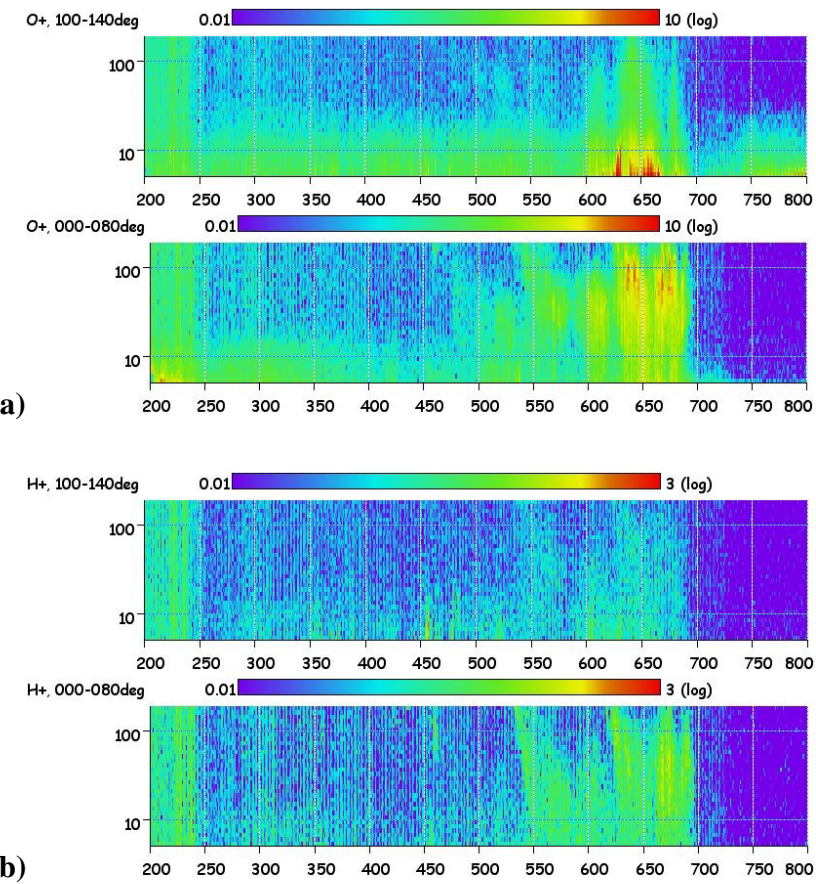

Fig. 2. Ion data overview as a function of flight time [s] from $\mathrm{T}+200 \mathrm{~s}$ to $\mathrm{T}+800 \mathrm{~s}$. (a): Energy spectra $[\mathrm{eV}]$ of oxygen, limited by pitch angle ranges of 100-140 degrees (top) and 0-80 degrees (bottom). (b): Energy spectra $[\mathrm{eV}]$ of protons, limited by pitch angle ranges of 100-140 degrees (top) and 0-80 degrees (bottom). [Color bar proportional to differential energy flux $\mathrm{eV} / \mathrm{cm}^{2} / \mathrm{s} / \mathrm{sr} / \mathrm{eV}$, arbitrary gain.]

electron precipitation, but they are not the subject of this paper.

Returning to Fig. 1, panel (c) shows the DC perpendicularto-B electric field structure, shown as north and east geomagnetic coordinates of the $\boldsymbol{E} \times \boldsymbol{B}$ flow, as calculated by Klatt (2005). Note the northward turning of the flow vector (and thus eastward turning of the electric field) during the region of ion upflow. The flows equatorward of the inverted $\mathrm{V}$ region are westward, as expected during this period of westward-travelling surges seen in the camera data. The transitional region between the inverted-Vs and the polar cap shows eastward flows, with an additional northward component after T+600 s. Panel (d) shows the various calculated conductivities (Klatt, 2005; MacDonald, 2004); these are discussed later in the paper.

The ambient density, not shown here, varied from 50000 $60000 / \mathrm{cc}$ on the upleg and downleg, to $20000 / \mathrm{cc}$ at apogee, with an enhancement to $55000 / \mathrm{cc}$ between $\mathrm{T}+620-630 \mathrm{~s}$.

This is a textbook south-to-north crossing of a premidnight substorm breakup. It is different however from previous reported examples such as the AMICIST rocket (Lynch et al., 1996) or the FAST case studies shown in Lynch et al. (2002) in that the poleward boundary region is not accompanied 


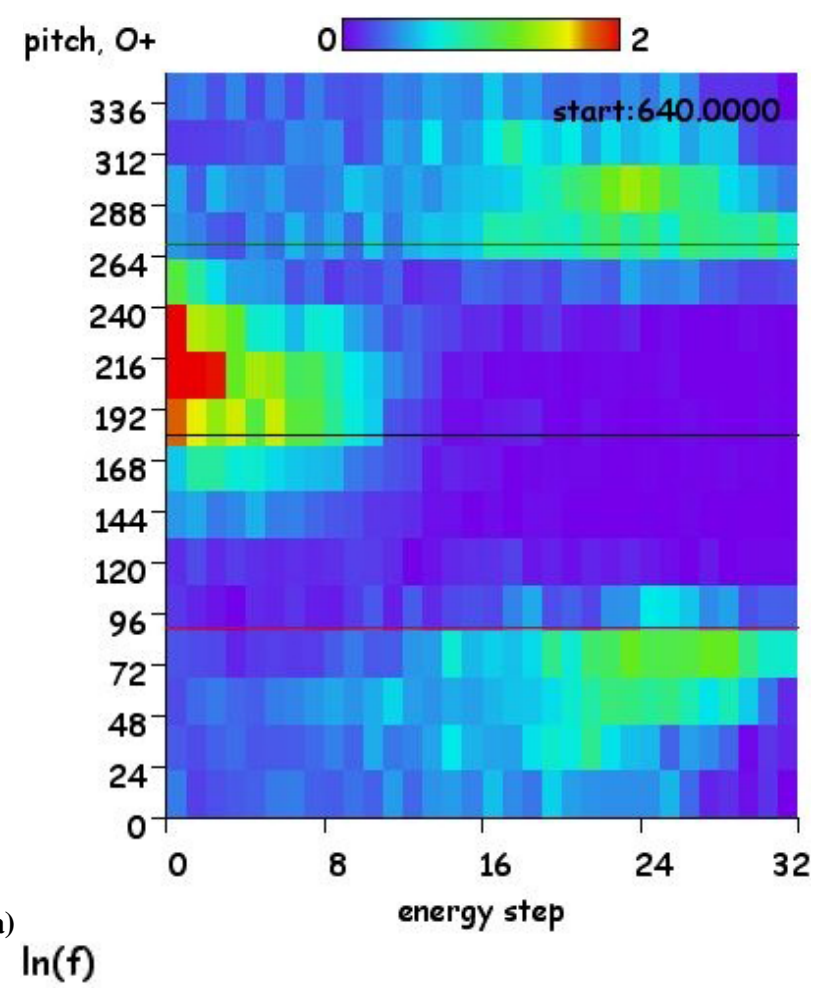

(a)

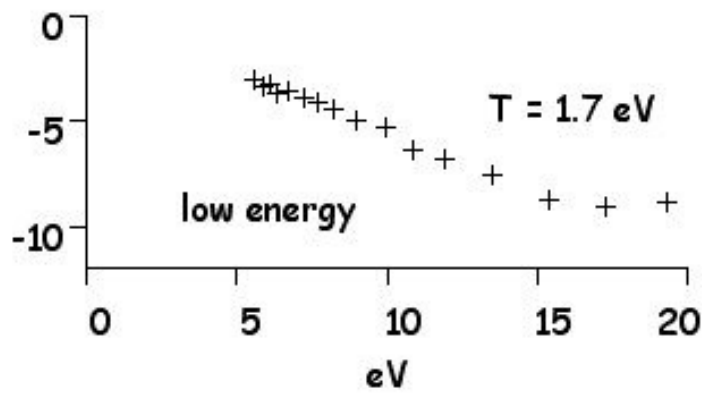

$\ln (f)$

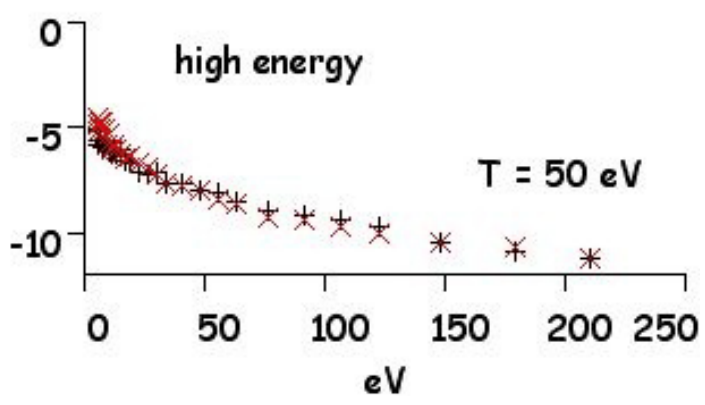

(b)

Fig. 3. (a) Example of oxygen pitch-energy distribution. (Color bar proportional to differential energy flux $\mathrm{eV} / \mathrm{cm}^{2} / \mathrm{s} / \mathrm{sr} / \mathrm{eV}$, arbitrary gain; as a function of pitch angle [deg] and energy step number of the logarithmic sweep.) (b) Plots of distribution function slope at $210^{\circ}$ (top) and $70^{\circ}$ (bottom). (Distribution function, $/ \mathrm{cc} /(\mathrm{km} / \mathrm{s})^{3}$, arbitrary gain, as a function of energy, eV). by intense broadband ELF (BBELF) wave activity and ion conics. This was a surprise, as the instrumentation for the SIERRA mission was designed around this expected signature. However, the SIERRA flight encountered a very high density ionosphere. SIERRA was at $40000 / \mathrm{cc}$ at $500 \mathrm{~km}$ altitude, where AMICIST saw $6000 / \mathrm{cc}$ at that altitude. Thus even though the absolute altitudes of the two missions were similar, a much denser plasma environment, typical of lower altitudes, was encountered by SIERRA. Thus SIERRA instead gives us a look at the low altitude, low energy precursors to BBELF-TAI, the initial upflow that feeds the higher altitude conics.

In this paper we will concentrate on the ion signatures from $\mathrm{T}+535-700 \mathrm{~s}$, with particular focus on the region of ion upflow from $T+620-670 \mathrm{~s}$. Two populations are to be examined: the downgoing oxygen and hydrogen in the $100 \mathrm{eV}$ energy range, and the upgoing low energy $(10 \mathrm{eV}$ and below) oxygen. In the detailed discussions below, we examine the signatures of these two populations, considering both the circulation patterns implied by the precipitating ions, and the drivers for the localization of the observed upflow. The upflow is delimited by electron precipitation energies, and coincides strongly with signatures of convection and conductivity.

\section{Ion data}

Figure 3 shows an example of the oxygen pitch angle-energy distribution, in units of differential energy flux (proportional to count rate) measured by the main payload Beeps instrument. The figure also shows examples of cuts of the distribution function $f$ at different pitch angles; the characteristic energy or "temperature" of the distribution is calculated by assuming a Maxwellian distribution in energy along a given pitch angle direction:

$k T=-0.434 / \frac{\partial(\log f)}{\partial E}$

The precipitating population has a characteristic energy in the 10s of eV. The upgoing population has an observed characteristic energy near $2 \mathrm{eV}$. Correcting the distribution function reference frame for known values of payload ram velocity and plasma flow gives a Maxwellian temperature in the plasma frame of $0.87 \mathrm{eV}$ at this time. This period thus shows some heating from typical ionospherically cold temperatures of well below $1 \mathrm{eV}$, but the population is not visible at other times for comparison. The proton data show a similar precipitating population, but no upgoing one; the drift energy (ram, convection, and upflow) of protons may not bring this population into the energy window of this detector.

\subsection{Ion precipitation}

Figure 4 shows energy spectra of protons and oxygen near 50 degrees pitch angle during the $\mathrm{T}+535-700 \mathrm{~s}$ time interval. 
As seen in Fig. 1, this time interval has electron precipitation consistent with the low altitude signature of a downward current region or an Alfvénic polar cap boundary region. Our interpretation of these dispersed, downgoing ions is that they are fed by upgoing ion heating and conics that have moved up the field line above the payload trajectory and then been reflected at some point by the time-varying (on the timescale of the motion of the ions) downward parallel electric field that is expected at a few thousand $\mathrm{km}$ altitude in such regions.

A simplistic velocity dispersion calculation on the 0 degree populations gives a reflection height of approximately $600 \mathrm{~km}$ above the observation point for the oxygen, and $1400 \mathrm{~km}$ for the protons. This calculation is very rough and is intended to give only an estimate of the source height. Using the oxygen dispersion signatures starting at $\mathrm{T}+525 \mathrm{~s}$, $\mathrm{T}+617 \mathrm{~s}$, and $\mathrm{T}+635 \mathrm{~s}$ gives source altitudes for each signature of $583 \mathrm{~km}, 611 \mathrm{~km}$, and $295 \mathrm{~km}$ above the observation point, respectively. Similarly, proton dispersions beginning at $\mathrm{T}+528 \mathrm{~s}, \mathrm{~T}+610 \mathrm{~s}$, and $\mathrm{T}+623 \mathrm{~s}$ give source altitudes of $1321 \mathrm{~km}, 1504 \mathrm{~km}$, and $1203 \mathrm{~km}$. The dispersionless signatures at the poleward edge cannot be interpreted with this simplistic model though it seems reasonable that they come from a related source. The dispersions are predominantly temporal signatures, as demonstrated by two points. First, all the dispersions are of the same sense, that is, highest speeds first followed by slower; for a spatial dispersion signature, it seems possible that the slower speed population could just as well be located equatorward of the higher speed population.

Second, if the signatures were spatial, they would appear with delays between the three payloads. Figure 5 shows pitch angle images from the three fixed-energy ion detectors on the three separated payloads. The lower energy end of the precipitating populations can be seen in the 0-60 degree and 300-360 degree regions of the spectrograms. The payloads are approximately $700 \mathrm{~m}$ apart at this time, and the relative velocity between the main payload and the plasma is $1800 \mathrm{~m} / \mathrm{s}$. The plasma is moving eastward to northeastward, and the payloads are moving mostly northward with a westward component. For the dispersion signatures to be spatial, depending on the orientation of structure boundaries, velocity related delays between the 3 payloads should be of the order of a second. No clear delay signatures between the ion spectra on the three payloads are seen, implying that the variations seen are predominantly temporal on the $1 \mathrm{~km}$ scales of the payload separations.

Thus we interpret this precipitating population as the reflected portion of upward moving ion conics generated at altitudes above the payload but not successful in escaping the low altitude end of the flux tube. The energization process reached ion temperatures of $10 \mathrm{~s}$ to $100 \mathrm{~s}$ of $\mathrm{eV}$ before the reflection occurred. No other local source of $10-100 \mathrm{eV}$ oxygen and protons is evident, and as we shall see in the next section, this is a region which is producing upwelling ions to move up into a transverse ion acceleration region. Other possibilities exist for feeding this ion precipitation (the

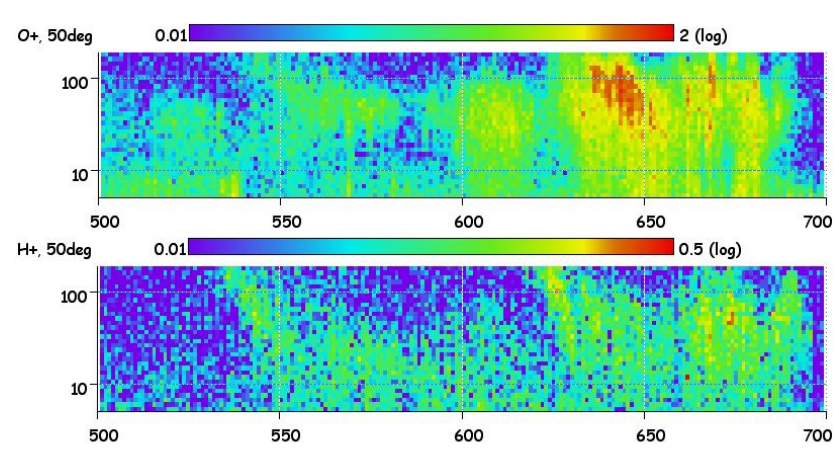

Fig. 4. Energy spectra $[\mathrm{eV}]$ of protons and oxygen near near $50^{\circ}$ pitch angle as a function of time $[\mathrm{s}]$ from $\mathrm{T}+500 \mathrm{~s}$ to $\mathrm{T}+700 \mathrm{~s}$. Color bar proportional to differential energy flux $\mathrm{eV} / \mathrm{cm}^{2} / \mathrm{s} / \mathrm{sr} / \mathrm{eV}$, arbitrary gain.]

cleft ion fountain (Lockwood, 1985); the interaction of Fregion patches with the polar cap boundary (Semeter, 2003)); but the local correspondence of this upflow and precipitation seems plausible. The coexistence of these downgoing dispersed ions with the upgoing thermal ion population could produce interesting anomalies in ISR spectra; a topic for a future effort.

\subsection{Ion upflow}

Next we consider the low energy upgoing population. Quantifying this population requires careful consideration of payload potential, payload ram velocity, plasma flow velocity, and ion mass. Since the signature is seen only in the oxygen channel, we assume an oxygen mass. The payload ram velocity is measured by the GPS system. The plasma flow velocity is measured by the electric field instruments. The payload potential is calculated from the electron temperature measured by the onboard TED instrument (MacDonald, 2004; MacDonald, 2006), and from the electron density measured by the HF wave experiment. At these energies, the observed ion population is no longer gyrotropic in the detector frame, as can be seen in Figs. 3 and 5.

Figure 6 shows the results of a model calculation which takes a thermal $\mathrm{O}^{+}$population, shifts it by the measured payload ram and plasma flow velocities, and accelerates it isotropically toward the charged payload by the spacecraft potential. The model is compared to the fixed energy ion detector data from the main payload. If no upflow velocity is included in the model, the peak count rate at the energy of the detector would be expected at the pitch angle shown by the position of the black line. If an upflow of $2 \mathrm{~km} / \mathrm{s}$ is included, the peak would be represented by the red line. The observed ions are moving upward at nearly $2 \mathrm{~km} / \mathrm{s}$. 


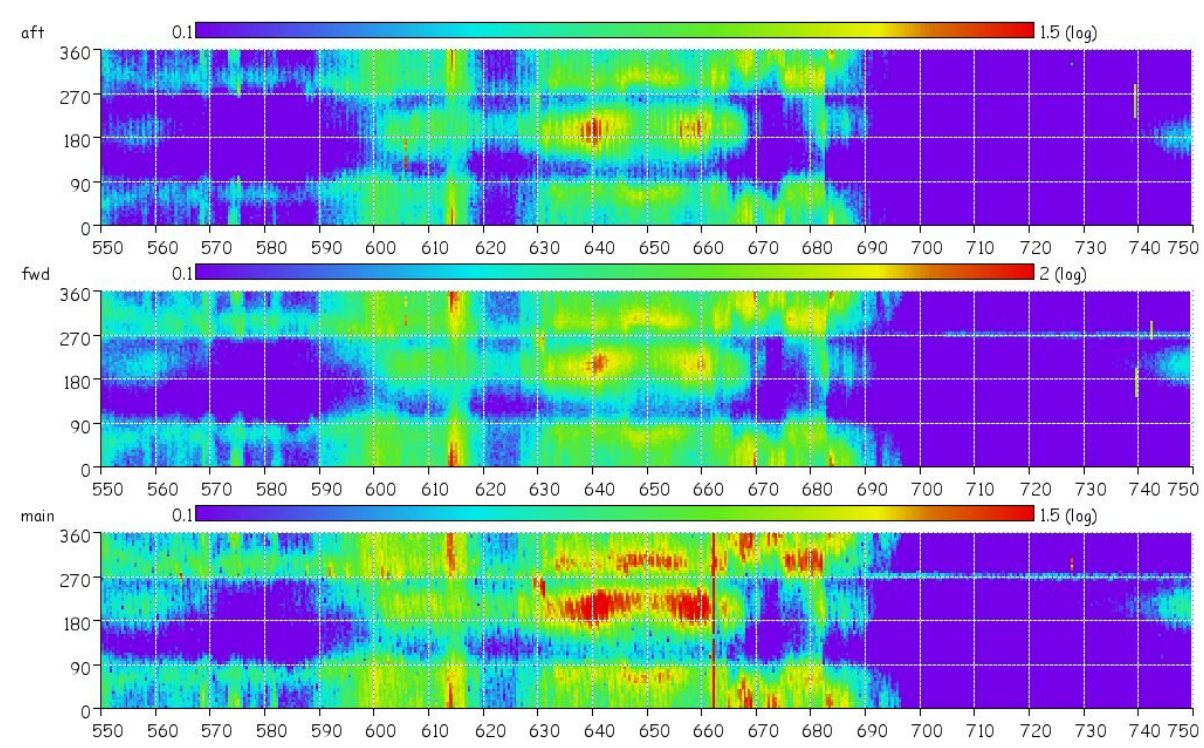

Fig. 5. Pitch angle spectrograms $[\mathrm{deg}]$ of $6 \mathrm{eV}$ ions as seen on the 3 separated payloads, as a function of time [s] from $\mathrm{T}+550 \mathrm{~s}$ to $\mathrm{T}+750 \mathrm{~s}$. (Color bar proportional to differential energy flux $\mathrm{eV} / \mathrm{cm}^{2} / \mathrm{s} / \mathrm{sr} / \mathrm{eV}$, arbitrary gain.)

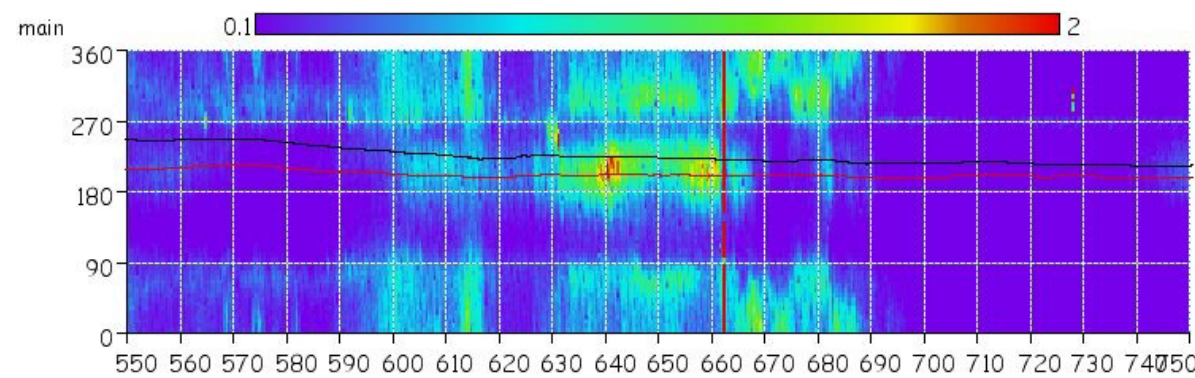

Fig. 6. Pitch angle spectrogram [deg] of $6 \mathrm{eV}$ ions (main) as a function of time [s] from $\mathrm{T}+550 \mathrm{~s}$ to $\mathrm{T}+750 \mathrm{~s}$. Overlaid with model calculation of expected peak pitch angle [deg] for upflow $=0 \mathrm{~m} / \mathrm{s}$ (black) and upflow $=2 \mathrm{~km} / \mathrm{s}$ (red). (Color bar proportional to differential energy flux $\mathrm{eV} / \mathrm{cm}^{2} / \mathrm{s} / \mathrm{sr} / \mathrm{eV}$, arbitrary gain.)

\section{Discussion}

The question for discussion is why the ion upflow is limited to the second half of the polar cap boundary region as delimited by the electron precipitation signature. Observations at higher altitudes find a clear relationship between Alfvénic or downward current electron signatures, and BBELF related ion conics (Lynch et al., 2002; Strangeway et al., 2005). With SIERRA we are observing the footpoint of these processes, and identification of the signatures which delimit the upflow can be used to identify the drivers of the upflow.

First we identify a number of things which do not appear to be related to the ion upflow onset. There is no sudden change in the plasma density. There is a localized enhancement in the density from $\mathrm{T}+620-630 \mathrm{~s}$, just before the onset of the upflow, but there is no overall decrease or enhancement in $n_{e}$ during the upflow region. Ion conics of various types have been seen to be localized in density depletions, both LHSS (Lynch et al., 1999) and BBELF (Arnoldy et al., 1996; Kintner et al., 1996, 1996b), so it is interesting that the upflow seeds for these processes do not appear to require a density depletion.

Next we consider the field signatures. The localized density enhancement at $\mathrm{T}+620-630 \mathrm{~s}$ is accompanied by a burst of downward Poynting flux (Klatt et al., 2005), but the ion upflow is poleward of these signatures; this may be a delayed response as discussed below. The upflow is also poleward of the largest magnetic field structure, from $T+610-620 \mathrm{~s}$ (not shown here). There is no sudden increase in observed wave activity at ELF frequencies, as would be expected from the transverse ion acceleration, BBELF correlation at higher altitudes.

Three features do emerge when studying the upflow region from T+620-700 s. (1) The electric field turns eastward and thus the plasma flow velocity turns northward. (2) The Alfvénic and Pedersen conductivities become comparable to 
each other. (3) The soft electron precipitation peak moves lower in energy, to below $100 \mathrm{eV}$. We consider these three features as possible drivers for the upflow.

\subsection{Convection and motions}

At $\mathrm{T}+600 \mathrm{~s}$, the plasma motion develops a strong northward component (see panel (c) of Fig. 1) that remains for the duration of the ion upflow period. Throughout the poleward boundary region, the DC electric field is strong, with convection speeds close to a $\mathrm{km} / \mathrm{s}$, but before the upflow, the flow is predominantly eastward. The coincidence of the oxygen upflow with the northward component of plasma motion in this substorm expansion leads to consideration that the activity may be moving into a region whose footpoint has not yet been evacuated of oxygen ions. We also wish to consider whether the observed upflow $(\mathrm{T}+620-700 \mathrm{~s})$ could be the source for the observed ion precipitation $(\mathrm{T}+450-700 \mathrm{~s}$.)

The poleward boundary region from $\mathrm{T}+530 \mathrm{~s}$ to $\mathrm{T}+700 \mathrm{~s}$ is $130 \mathrm{~km}$ across in the north-south direction; the relative northward component of motion between the payloads and the plasma is approximately $1000 \mathrm{~m} / \mathrm{s}$ from $\mathrm{T}+490-590 \mathrm{~s}$, and approximately $600 \mathrm{~m} / \mathrm{s}$ from $\mathrm{T}+600-700 \mathrm{~s}$. Is it reasonable that ions upflowing at the poleward edge of this border should move up in altitude, be reflected from above, and precipitate back down to a point which is as much as $130 \mathrm{~km}$ equatorward of where the boundary edge is? This depends on expectations for the upward and downward velocities, and for the motion of the edge during that time. Assuming that the entire flux tube moves as a unit, we need to separate our expectations for convective $(\boldsymbol{E} \times \boldsymbol{B})$ motion, and proper motion. Convection cannot move the circulating ions away from the "edge" of the structure as the edge will also convect. Proper motion of arc structures, however, can be independent of plasma flow.

Given that we observe the upflow at $2 \mathrm{~km} / \mathrm{s}$, and the precipitation downflow at approximately $35 \mathrm{~km} / \mathrm{s}$, we can estimate that the average upward velocity along the flux tube is somewhere between these two, depending on the altitude extent of the higher altitude transverse ion acceleration process. If the reflection happens in a localized altitude range, the downflow velocity is simply a reflection of the maximum attained velocity, or $35 \mathrm{~km} / \mathrm{s}$. The dispersion signatures imply (for oxygen) a reflection altitude $600 \mathrm{~km}$ above the observation point. The upleg thus requires $600 \mathrm{~km} /(2$ to $35 \mathrm{~km} / \mathrm{s})$, or 300 to $17 \mathrm{~s}$. The downleg requires $17 \mathrm{~s}$. Can the arc front have moved $130 \mathrm{~km}$ in 317 to $34 \mathrm{~s}$ ? This is a proper motion of 0.4 to $3.8 \mathrm{~km} / \mathrm{s}$.

To decide if this is feasible we look to the ground camera data for the flight. Unfortunately, the poleward edge of the arc is either covered by clouds or is subvisual. Between $\mathrm{T}+560$ and $\mathrm{T}+580$, the payload footpoint leaves the last visible arc in the camera data. We can consider the evolution of the arc system before this time. A series of westward travelling surges moves across the camera field of view. In par- ticular, from $\mathrm{T}+481$ to $\mathrm{T}+540$, an arc $22 \mathrm{~km}$ wide is added to the front of the system from east to west, effectively moving the front edge of the arc system $26 \mathrm{~km}$ northward in $39 \mathrm{~s}$. This $0.67 \mathrm{~km} / \mathrm{s}$ change is within the required range of 0.4 to $3.8 \mathrm{~km} / \mathrm{s}$ proper motion; while individual arcs are also seen to recede southward, overall the net effect is of a poleward expansion.

We can also examine our multiple-point ion data, but this does not help much. We can measure the motion of structures in the observed ion heating, but these motions may or may not correspond to proper motion of the arc edge. There is also ambiguity between motion of the structure edge, and motion along the structure edge, which is not distinguishable without good camera data.

\subsection{Conductivities and reflections}

The second feature of the ion upflow region is that it is where the reflection coefficient for Alfvén wave activity approaches zero. Treating the ionosphere as a discrete boundary, the reflection coefficient is given by (Lysak, 1985; Knudsen, 1990) $R=\frac{\Sigma_{A}-\Sigma_{P}}{\Sigma_{A}+\Sigma_{P}}$

and determines the amount of absorption of Alfvénic power at the lower boundary of the flux tube. Here, $\Sigma_{P}$ is the Pedersen conductivity and $\Sigma_{A}$ is the Alfvén conductivity $\left(\mu_{o} V_{A}\right)^{-1}$. Where $R$ goes to zero, there should be enhanced transmission of Alfvénic power down to the bottom of the ionosphere, and the absorbed energy may seed ion upflow. Panel (d) of Fig. 1 shows various measures of (inverse) conductivity in the context of the particle data. These conductivities were calculated by Klatt (2005) and MacDonald (2004), and are reproduced here to show the relationship to the upflowing ions. We compare the Alfvén velocity calculated from the measured density (red trace); the E/B velocity from the measured field variations (black trace), and the (inverse) Pedersen conductivity caused by the measured electron precipitation (Reiff, 1984). The Pedersen conductivity is calculated from the measured electron precipitation and registers only the contribution to $\Sigma_{P}$ from this observed precipitation. For the first half of the flight, the E/B velocity is close to the inverse Pedersen conductivity, consistent with expectations of the quasi-steady fields below inverted-V arcs. Once the payload moves into the broader-energy Alfvénic precipitation, the E/B velocity approaches the local Alfvén speed (Knudsen, 1990), and the Pedersen conductivity enhancement weakens. During the region of ion outflow, all three quantities overlap. The implications of this correspondence are beyond the scope of this paper but we present it as an observational data point that may be of interest to modellers.

\subsection{Soft electron precipitation}

Thirdly we consider the soft electron precipitation seen in and just before the ion upflow region. In Fig. 1 we 


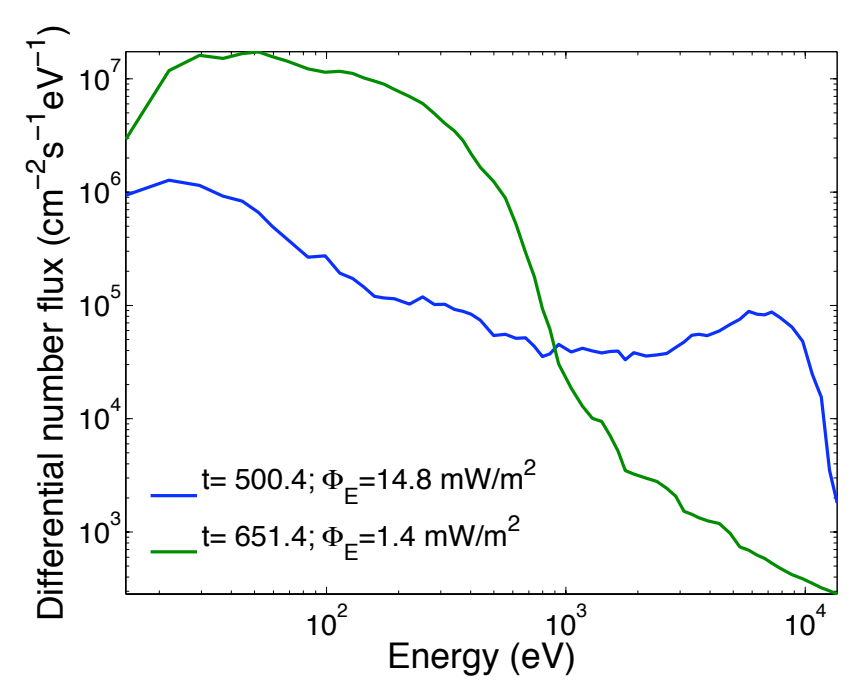

Fig. 7. Data input for modelling of precipitation-driven heating effects: input spectra from SIERRA at two times; $0^{\circ}$ pitch angle data from the electron detector, calculated as differential number flux, at $\mathrm{T}+500 \mathrm{~s}$ and $\mathrm{T}+652 \mathrm{~s}$.

see high-energy inverted-V arc precipitation up to $\mathrm{T}+530 \mathrm{~s}$. From then until $\mathrm{T}+700 \mathrm{~s}$, there is a region of Alfvénic precipitation of variable energy. Within this Alfvénic precipitation region, there is a subdivision before and after $\mathrm{T}+620 \mathrm{~s}$, at which time the average energy drops significantly, from above $100 \mathrm{eV}$ to below. This is also the subdivision of this region into the part without ion upflow, and the part with ion upflow.

The low energy of this precipitation has important implications for interactions with the ionosphere, as this softer precipitation deposits its energy in a different way. The harder precipitation deposits its energy at low altitudes, while the very soft precipitation deposits its energy at higher altitudes. Some of this energy deposition occurs via Coulomb collisions which serve as a heat source to the ambient ionospheric electrons. Above $\sim 300 \mathrm{~km}, T_{e}(\mathrm{z})$ is controlled by thermal conduction. This works in two ways. There is direct conduction between hot precipitating electrons and thermal background electrons, producing a pressure gradient which can transport plasma along the field line. Thermal conduction from these transported electrons provides a second, indirect, heating source. Since there are no heat sinks at these altitudes, $T_{e}$ can grow very large with just a small flux of hot magnetospheric electrons, given enough time.

The relationship to hard electron precipitation is as follows. Consider a $1 \mathrm{keV}$ beam of inverted $\mathrm{V}$ electrons. Around $150 \mathrm{~km}$ altitude, this beam will begin a cascade of ionizing collisions, ultimately making about 30 electron-ion pairs per primary electron. Ionization will stop when the secondary electron energy reduces to below $18 \mathrm{eV}$, the average ionization potential. This leaves a bath of electrons with energies below $18 \mathrm{eV}$, but still very hot compared to the back- ground. Thus it takes, on average, $35 \mathrm{eV}$ to generate each electron-ion pair (about twice the ionizing energy) (Thayer and Semeter, 2004). The incident primary kinetic energy flux is partitioned to roughly $50 \%$ ionization, $48 \%$ heating, and $2 \%$ excitation. The models presented in Thayer and Semeter (2004) consider current closure altitudes (80-200 km) where the vast majority of magnetospheric energy is deposited. In this region, $T_{e}=T_{i}=T_{n}$ (roughly) because of collisions. Now, the soft flux seen in the SIERRA flight is like injecting this bath of below $18 \mathrm{eV}$ secondary electrons at a very high altitude. This flux carries very little kinetic energy but, because it controls the thermal structure at these altitudes, it may be important for ion outflow, which is what the simulation runs below are suggesting.

We examine the details of this situation by comparing the modeled effects of two different precipitating electron spectra on ionospheric upflows. The first is an "inverted V" spectrum, a high energy distribution associated with auroral arcs, and the second is a "flat-top" distribution, a lower energy distribution usually seen by spacecraft near the polar cap boundary. A plot of both of these distributions is shown in Fig. 7. Precipitating electrons deposit energy via collisions with ionospheric particles in three ways: through ionizing collisions with neutral species, through excitation of ionospheric species, and through heating of the thermal electrons in the ionosphere. The latter effect is particularly important for our case since heating can cause expansion and upwelling of the ionospheric plasma. The energy dependence of the spectrum determines the effects of the precipitation in two ways. First, high energy electrons travel farther into the ionosphere than lower energy electrons before depositing their energy. Second, for the precipitation at any particular altitude, the low energy electrons will deposit energy in the form of heating and high energy electrons will yield ionization. Based on these considerations we can expect that a low energy precipitation such as the flat-top distribution will have a greater effect on upflow in the topside ionosphere since it will heat the thermal electron population at those altitudes. Furthermore, the soft precipitation heat input to the plasma at F-region and topside altitudes will not be lost quickly due to collisions with the neutral gas. The neutral density is quite low at these altitudes as compared to the E-region, where the high energy electrons deposit their energy.

The computer model that we use for this case study is TRANSCAR and has been described most recently in (Lilensten et al., 2002; Blelly et al., 2005). TRANSCAR is a one-dimensional time-dependent model of the ionosphere that solves for the density $n_{s}$, drift velocity $\mathbf{u}_{s}$, temperature $T_{s}$, and heat flow $\mathbf{q}_{s}$ for seven different ion species $\left(s=\mathrm{O}^{+}, \mathrm{H}^{+}, \mathrm{N}^{+}, \mathrm{N}_{2}^{+}, \mathrm{NO}^{+}, \mathrm{O}_{2}^{+}\right.$, and $\left.e^{-}\right)$. TRANSCAR includes a fluid module which computes a numerical solution to the 8-moment equations along geomagnetic field lines and a kinetic module, fully described by Lummerzheim and Lilensten (1994), that solves the transport equation for superthermal electrons. The fluid and kinetic modules of 
TRANSCAR are dynamically coupled; the fluid module provides thermal electron density and temperature to the kinetic module and the kinetic module provides ionization and heating rates to the fluid module. The background neutral thermospheric densities and temperatures for TRANSCAR are provided by the MSIS90 model (Hedin, 1991). TRANSCAR is able to describe several processes that contribute to magnetosphere-ionosphere coupling and that are important for ion upflow and outflow. The effects of electron precipitation, frictional heating from convection electric fields, downward heat flow from the magnetosphere into the ionosphere, and field aligned currents carried by thermal electrons are included in the model.

We perform two separate simulations using as input the two different types of electron precipitation measured by the SIERRA rocket. The latitude of each simulation is set at $65^{\circ}$ (Poker Flat, AK), and the simulation date is set to 14 January 2002. The field aligned currents and neutral winds are set to zero for the simulations, and the convection electric fields are provided by the SIERRA payload (Fig. 1c). The heat flow from the magnetosphere is not measured by SIERRA so we have adopted a representative high-latitude winter value derived from Blelly and Alcayde (1994) of $-1 \mu \mathrm{W} / \mathrm{m}^{2}$. The electron precipitation for our two simulations, which is imposed at the top boundary of the kinetic module, is provided by the SIERRA measurements shown in Fig. 7. For each of the two simulations we allow TRANSCAR to run for a full $11 \mathrm{~h}$ before we switch on the precipitation at 23:23 LT, the launch time for SIERRA. By allowing $11 \mathrm{~h}$ before switching on the precipitation, we prevent our results from being affected by the initial conditions of the simulation. Once the precipitation is switched on, it is left on for a $1.5 \mathrm{~h}$ so that the two simulations show the "step response" of the ionosphere to the precipitation spectra measured by SIERRA.

Figure 8 shows the results of our simulations with TRANSCAR. The left panels of Fig. 8 show the effects of the harder precipitation on oxygen ion upflow $(\mathrm{T}+500 \mathrm{~s})$, and the right panels of Fig. 8 the same for the softer precipitation $(T+652 \mathrm{~s}$.) These figures of the ionospheric response show both altitude profiles and temporal evolution of the upflow events on the flux tube simulated by TRANSCAR; this is what an incoherent scatter radar would observe if it were pointed parallel to the geomagnetic field and moving at the local convection speed with the flux tube.

The soft precipitation has a markedly stronger effect on ion upflow, bringing the oxygen ion outflow peak velocity to $2 \mathrm{~km} / \mathrm{s}$ at $1000 \mathrm{~km}$ altitude, as compared to $700 \mathrm{~m} / \mathrm{s}$ for the inverted $\mathrm{V}$ spectrum. The oxygen ion upflows for each case are similar in the sense that they are both transient features of the ionospheric response to the precipitation. The delay in the onset of this upflow may be an explanation for the observation (see Fig. 1) that the strongest upflow (after T+625 s) is delayed from the strongest soft electron precipitation at $\mathrm{T}+620 \mathrm{~s}$. Even though the precipitation is left on for $1.5 \mathrm{~h}$ in the simulation, the upflow velocities start to decrease af-
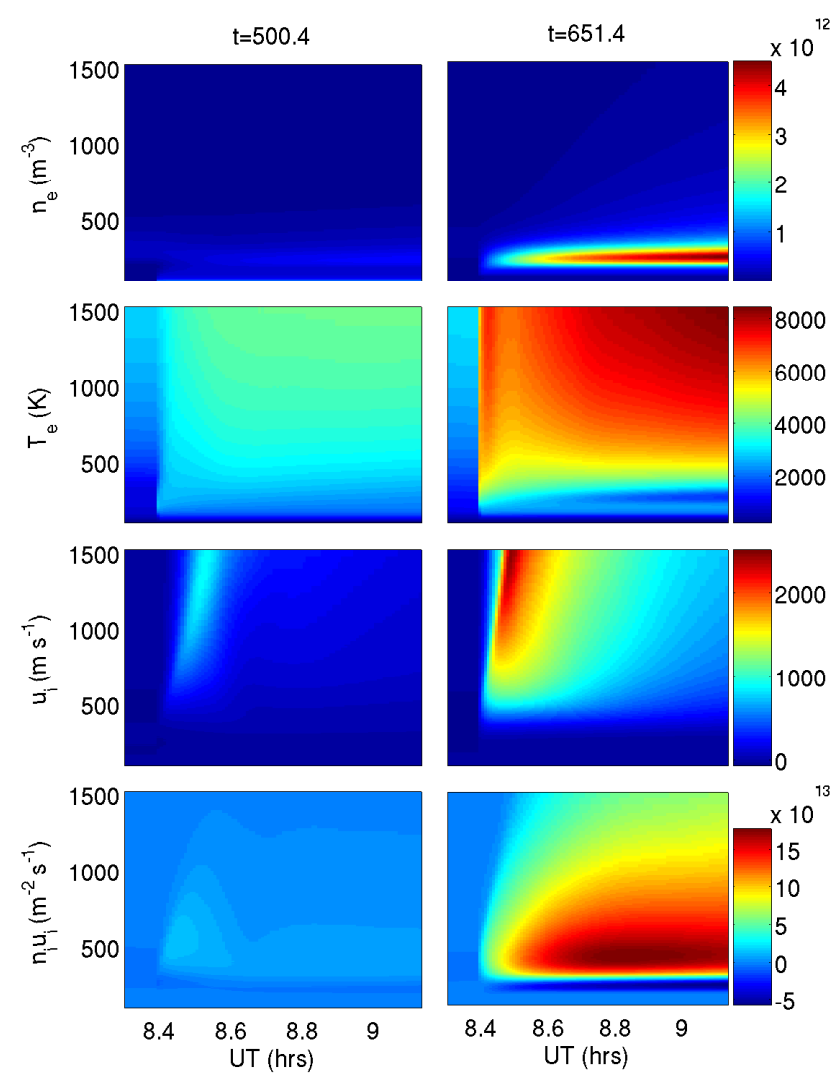

Fig. 8. Modelling of precipitation-driven heating effects: left panels, from input at $\mathrm{T}+500 \mathrm{~s}$; right panels, from input at $\mathrm{T}+651.4 \mathrm{~s}$.

ter only about $15 \mathrm{~min}$. The oxygen ion fluxes also show the transient behavior, but reveal some interesting differences for the two cases. For the case of the soft precipitation, the flux remains quite large even after $1.5 \mathrm{~h}$ of exposure to the precipitation. The simulations show that this type of precipitation spectrum is a source of F-region ionization and ion upflow. This may explain the prolonged time that the upward flux remains large since the upflow event is supplied with a steady source of new plasma. Optical emissions associated with such flat-top distributions have been previously studied in the context of Alfvénic electron acceleration (Chaston et al., 2003). Here we have shown that these distributions may also be an important driver for $\mathrm{O}+$ ion outflow.

As previously discussed, some of the energy of the precipitating electrons goes into heating the thermal electron gas. Our simulations show that this heating mechanism causes a temporarily sharpened upward pressure gradient in the thermal electron population. The sharpened electron pressure gradient increases the polarization electric field in the plasma and accelerates the ions upward. These types of ion flows are commonly observed in auroral ISR data (Forme and Fontaine, 1999) and have been simulated by previous modeling efforts (Su, 1999). 


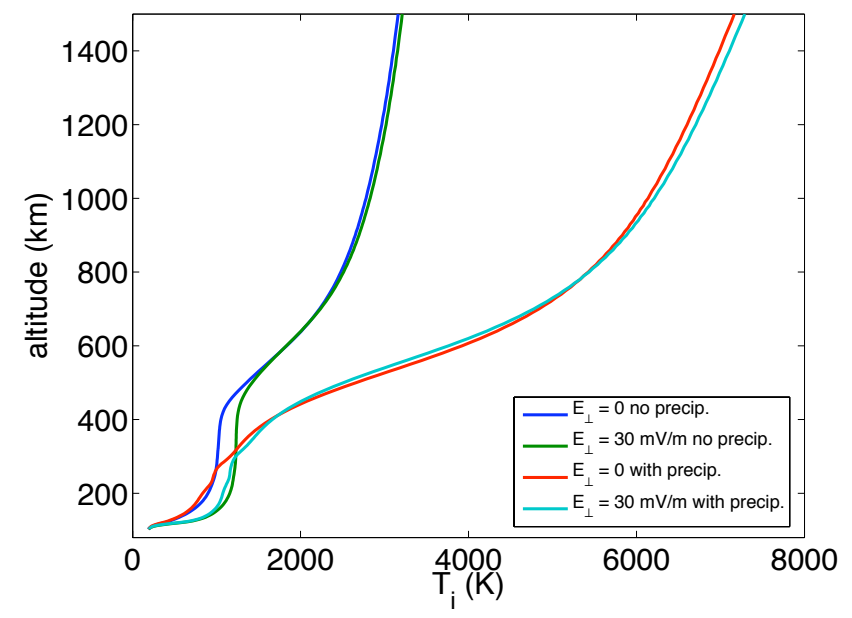

Fig. 9. Modelled ion temperature profiles with and without convection and soft precipitation drivers.

Turning on frictional heating effects (Type 1) in the model based on the plasma flows from the observed $30 \mathrm{mV} / \mathrm{m}$ electric fields has relatively little net effect compared to the strong heating caused by the soft precipitation. Figure 9 shows that the convection driven heating increases the ion temperatures by up to a few hundred degrees $\mathrm{K}$ below $500 \mathrm{~km}$ altitude, but above $500 \mathrm{~km}$ the heating profile is dominated by the precipitation-driven effects.

Both the ion upflow and the ion temperature enhancement shown in the model will enhance higher altitude transverse ion heating mechanisms such as described by Chaston et al., (2006). The upflow can be seen as seeding this higher altitude transverse ion acceleration, which we subsequently observe as the higher energy ion precipitation discussed in Sect. 3.1.

\section{Conclusions}

The SIERRA sounding rocket data provide a detailed in situ examination of the low altitude signatures of ion outflow, which are more typically studied with the bulk property remote sensing methods of radars. We see both in this example, and in the dayside example of Frederick-Frost et al. (2007) that soft electron precipitation appears as the trigger for this process. With the SIERRA data we can see the details of both the electron precipitation and the ion upflow, as well as an indirect observation of the higher altitude transverse ion acceleration process, through the ions which do not escape but precipitate back down past the payload. These observations are consistent with a multi-stage process for ion outflow which begins at low altitudes through soft electron precipitation driven heating and upflow, and moves ionospheric ions to higher altitudes where transverse ion heating processes can act. We hope that this detailed case study can provide a test point for models of ionospheric outflow and magnetosphereionosphere coupling.

Acknowledgements. The authors acknowledge support from NSF ATM-0443728 and ATM-0547934.

Topical Editor M. Pinnock thanks K. Yumoto and another anonymous referee for their help in evaluating this paper.

\section{References}

André, M., Norqvist, P., Andersson, L., Eliasson, L., Eriksson, A., Blomberg, L., Erlandson, R., and Waldemark, J.: Ion energization mechanisms at $1700 \mathrm{~km}$ in the auroral region, J. Geophys. Res., 103, 4199-4222, 1998.

Arnoldy, R. L., Lynch, K. A., Kintner, P. M., Bonnell, J., Moore, T. E., and Pollock, C. J.: Scifer - Structure of the Cleft Ion Fountain at $1400 \mathrm{~km}$ Altitude, Geophys. Res. Lett., 23, 1869-1872, 1996.

Blelly, P. and Alcaydé, D.: Electron heat flow in the auroral ionosphere inferred from EISCAT VHF observations, J. Geophys. Res., 99, 13 181-13 188, 1994.

Blelly, P., Lathuillére, C., Emery, B., Lilensten, J., Fontanari, J., and Alcaydé, D.: An extended TRANSCAR model including ionospheric convection: simulation of EISCAT observations using inputs from AMIE, Ann. Geophys., 23, 419-431, 2005, http://www.ann-geophys.net/23/419/2005/.

Bonnell, J., Kintner, P. M., Wahlund, J. E., Lynch, K. A., and Arnoldy, R. L.: Interferometric Determination of Broadband ELF Wave Phase Velocity within a region of transverse ion acceleration, Geophys. Res. Lett., 23, 3297-3300, 1996.

Carlson, C. W., Curtis, D. W., Paschmann, G., and Michael, W.: An instrument for rapidly measuring plasma distribution functions with high resolution, Adv. Space Res., 2, 67-70, 1983.

Chaston, C.: Width and brightness of auroral arcs driven by intertial Alfven waves, J. Geophys. Res., 108, 1091, doi:10.1029/2001JA007 537, 2003.

Chaston, C.: Ionospheric erosion by Alfven waves, J. Geophys. Res., 111, A03206, doi:10.1029/2005JA011 367, 2006.

Doe, R. A., Mendillo, M., Vickrey, J., Zanetti, L., and Eastes, R.: Observations of nightside auroral cavities, J. Geophys. Res., 98, 293-310, 1993.

Forme, F. R. E. and Fontaine, D.: Enhanced ion acoustic fluctuations and ion outflows, Ann. Geophys., 17, 182-189, 1999, http://www.ann-geophys.net/17/182/1999/.

Frederick-Frost, K., Lynch, K. A., Kintner, P., et al.: SERSIO: Svalbard EISCAT rocket study of ion outflows, J. Geophys. Res., 112, A08307, doi:10.1029/2006A011942, 2007.

Hedin, A. E.: Extension of the MSIS thermospheric model into the middle and lower atmosphere, J. Geophys. Res., 96, 1159-1172, 1991.

Kintner, P.: The SCIFER Experiment, Geophys. Res. Lett., 23, 1865-1868, 1996.

Kintner, P. M., Bonnell, J., Arnoldy, R., Lynch, K., Pollock, C., and Moore, T.: SCIFER - Transverse Ion Acceleration and Plasma Waves, Geophys. Res. Lett., 23, 1873-1876, 1996.

Klatt, E., Kintner, P., Seyter, C., et al.: SIERRA observations of Alfvenic processes in the topside auroral ionosphere, J. Geophys. Res., 110, A10512, doi:10.1029/2004JA010883, 2005. 
Knudsen, D., Clemmons, J., and Wahlund, J.: Correlation between core ion energization, suprathermal electron bursts, and broadband ELF plasma waves, J. Geophys. Res., 103, 4171-4186, 1998a.

Knudsen, D. J. and Wahlund, J.: Core Ion Flux bursts within solitary Kinetic Alfvén Waves, J. Geophys. Res., 103, 4157-4170, 1998b.

Knudsen, D. J., Kelley, M. C., Earle, G. D., Vickrey, J. P., and Boehm, M. H.: Distinguishing Alfvén waves from quasi-static field structures associated with the discrete aurora: sounding rocket and HILAT satellite measurements, Geophys. Res. Lett., 17, 921-924, 1990.

Lilensten, J. and Blelly, P.: The TEC and F2 parameters as tracers of the ionosphere and thermosphere, J. Atmos. Solar Terr. Phys., 64, 775, doi:10.1016/S1364-6826(02)00079-2, 2002.

Lockwood, M., Chandler, M. O., Horwitz, J. L., Jr., J. H. W., Moore, T. E., and Chappell, C. R.: The cleft ion fountain, J. Geophys. Res., 90, 9736-9748, 1985.

Lummerzheim, D. and Lilensten, J.: Electron transport and energy degradation in the ionosphere: Evaluation of the numerical solution, comparison with laboratory experiments and auroral observations, Ann. Geophys., 12, 1039-1051, 1994, http://www.ann-geophys.net/12/1039/1994/.

Lynch, K. A., Arnoldy, R. L., Kintner, P. M., and Vago, J. L.: Electron Distribution Function Behavior During localized transverse ion acceleration events in the topside auroral zone, J. Geophys. Res., 99, 2227-2242, 1994.

Lynch, K. A., Arnoldy, R. L., Bonnell, J., and Kintner, P. M.: The AMICIST Auroral sounding rocket - A comparison of transverse ion acceleration methods, Geophys. Res. Lett., 23, 3293-3296, 1996.

Lynch, K. A., Arnoldy, R. L., Kintner, P. M., Schuck, P., Bonnell, J., and Coffey, V.: Auroral Ion Acceleration from Lower Hybrid Solitary Structures: A Summary of Sounding Rocket Observations, J. Geophys. Res., 104, 28 515-28 534, 1999.

Lynch, K. A., Bonnell, J. W., Carlson, C. W., and Peria, W. J.: Return current region aurora: $\mathrm{E}_{\|}, \mathrm{j}_{z}$, particle energization and BBELF wave activity, J. Geophys. Res., 107, 1115, doi:10.1029/2001JA900 124, 2002.

Lysak, R. L.: Auroral electrodynamics with current and voltage generators, J. Geophys. Res., 90, 4178-4190, 1985.

Lysak, R. L. and Song, Y.: Non-local interactions between electrons and Alfvén waves on auroral field lines, J. Geophys. Res., 110, A10506, doi:10.1029/2004JA010803, 2005.

MacDonald, E. A.: Sounding rocket measurements of thermal electrons in active nightside aurora, Ph.D. thesis, University of New Hampshire, Durham, 2004.

MacDonald, E. A., Lynch, K., Widholm, M., Arnoldy, R., Klatt, E., Kintner, P., Samara, M., and LaBelle, J.: Insitu measurement of thermal electrons on the SIERRA nightside auroral sounding rocket, J. Geophys. Res., 111, A12310, doi:10.0129/2005JA011493, 2006.

Moore, T. E., Chandler, M. O., Pollock, C. J., Reasoner, D. L., Arnoldy, R. L., Austin, B., Kintner, P. M., and Bonnell, J.: Plasma heating and flow in an auroral arc, J. Geophys. Res., 101, 5279-5298, 1996.
Reiff, P. H.: Models of auroral-zone conductances, in: Magnetospheric Currents, edited by Potemra, T. A., vol. 28 of AGU Monograph Series, p. 180, American Geophysical Union, Washington, D.C., 1984.

Samara, M.: Sounding rocket investigations of whistler, upper hybrid and Langmuir waves in the auroral ionosphere, Ph.D. thesis, Dartmouth College, 2005.

Semeter, J., Heinselman, C., Thayer, J., and Doe, R.: Ion upflow enhanced by drifting F-region plasma structure along the nightside polar cap boundary, Geophys. Res. Lett., 30, 2139, doi:10.1029/2003GL017747, 2003.

Semeter, J., Heinselman, C., Sivjee, G., et al.: Ionospheric response to wave-accelerated electrons at the poleward auroral boundary, J. Geophy. Res., 110, A11310, doi:10.1029/2005JA011226, 2005.

St.-Maurice, J., Hanson, W., and Walker, J.: Retarding potential analyzer measurement of the effect of ion-neutral collisions on the ion velocity distribution in the auroral ionosphere, J. Geophys. Res., 81, 5438-5446, 1976.

Strangeway, R., Ergun, R., Su, Y., Carlson, C., and Elphic, R.: Factors controlling ionospheric outflows as observed at intermediate altitudes, J. Geophys. Res., 110, A03221, doi:10.1029/2004JA010829, 2005.

Streltsov, A. V. and Lotko, W.: Small-scale electric fields in downward current channels, J. Geophys. Res., 108, 1289, doi:10.1029/2002JA009806, 2003.

Streltsov, A. V. and Marklund, G. T.: Divergent electric fields in the downward current channels, J. Geophys. Res., 3, A07204, doi:10.1029/2005JA11196, 2006.

Stromme, A., Belyey, V. Grydeland, T., et al.: Evidence of naturally occurring wave-wave induced interactions in the polar ionosphere and its relation to naturally enhanced ion acoustic lines, Geophys. Res. Lett., 32, L05103, doi:10.1029/2004GL02039, 2004.

Su, Y., Caton, R., Horwitz, J., and Richards, P.: Systematic modeling of soft-electron precipitation effects on high-latitude $F$ region and topside ionospheric upflows, J. Geophys. Res., 104, 153164, 1999.

Thayer, J. and Semeter, J.: The convergence of magnetospheric energy flux in the polar atmosphere, J. Atmos. Solar-Terr. Phys., 66, 807, doi:10.1016/j.jastp.2004.01.035, 2004.

Wahlund, J., Opgenoorth, H. J., Forme, R., Persson, M., , Haggstrom, I., and Lilensten, J.: Electron energization in the topside auroral ionosphere: on the importance of ion-acoustic turbulence, J. Atm. Terr. Phys., 55, 623-645, 1993.

Wahlund, J. E., Eriksson, A. I., Holback, B., Bonnell, M. H. B., Kintner, P. M., Seyler, C. E., Clemmons, J. H., Eliasson, L., Knudsen, D. J., Norqvist, P., and Zanetti, L. J.: Broadband ELF plasma emission during auroral energization 1. Slow ion acoustic waves, J. Geophys. Res., 103, 4343-4376, 1998.

Young, D. T., Bame, S. J., Thomsen, M. F., Martin, R. H., Burch, J. L., Marshall, J. A., and Reinhard, B.: $2 \pi$ radian field-of-view toroidal electostatic analyzer, Rev. Sci. Instrum., 59, 743-751, 1988. 